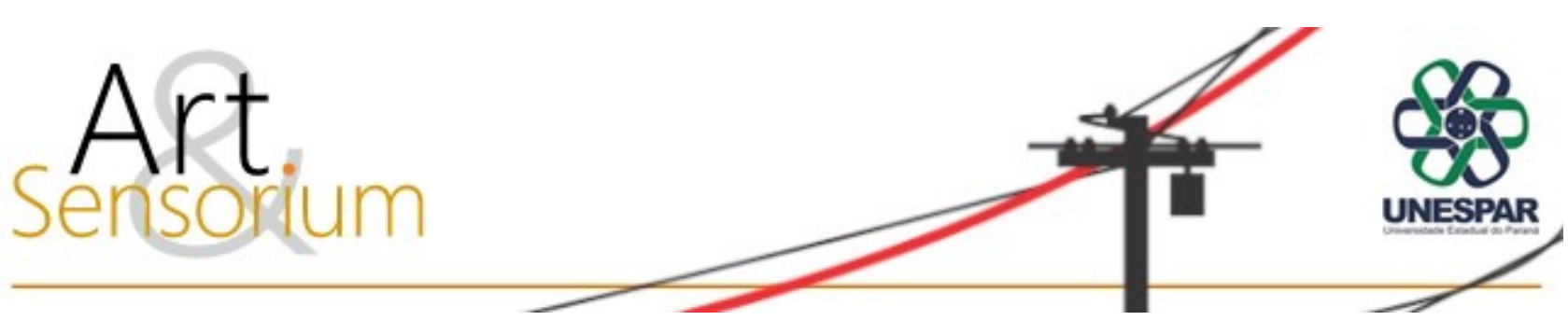

\title{
ARTE, JOGO E LUDICIDADE: UMA EXPERIÊNCIA EMERGENCIAL DE ENSINO E EXTENSÃO REMOTOS
}

https://doi.org/10.33871/23580437.2021.8.2.015-031

\author{
Fabricio Vaz Nunes ${ }^{1}$ \\ Anderson Bogéa ${ }^{2}$ \\ Luiz Carlos Sereza ${ }^{3}$
}

RESUMO: Este artigo se dedica a expor algumas reflexões acerca das relações entre arte e jogo surgidas a partir da experiência de ensino remoto emergencial intitulada Jogos, Poéticas, Estratégias e Gameficação - JPEG, como parte do Campo Remoto, atividade remota emergencial desenvolvida no âmbito dos cursos de artes visuais da Universidade Estadual do Paraná - Campus Curitiba I, no ano de 2020, em razão da pandemia da Covid-19. Dessa experiência surgiu um projeto de extensão universitária chamado Fabrica Ludi, cujo objetivo é desenvolver jogos que têm por tema o universo das artes visuais. Tomando como ponto de partida as teorizações de Johann Huizinga (Homo ludens) e Roger Caillois (Os jogos e os homens) sobre os jogos, são estabelecidos paralelos com o conceito filosófico da autonomia da arte e com a presença da noção de jogo em pensadores como Friedrich Schelling e Ludwig Wittgenstein. A partir desse arcabouço teórico, são apresentados e discutidos dois jogos criados pela equipe do projeto Fabrica Ludi: The Artworld e Gira-gira da arte, em que os conceitos de "mundo da arte" de Arthur Danto e o de ironia como tropo formativo da historiografia, de Hayden White, são empregados para estabelecer situações de ludicidade.

Palavras-chave: Ensino de arte; Jogos; Estética.

\footnotetext{
${ }^{1}$ Professor adjunto da Universidade Estadual do Paraná, Campus I (Escola de Música e Belas Artes do Paraná). Mestre em História da Arte pela Universidade Estadual de Campinas e Doutor em Letras pela Universidade Federal do Paraná. Atualmente desenvolve pesquisas sobre as relações entre arte e literatura, com ênfase na literatura fantástica latinoamericana. Curitiba/PR, Brasil. Link para o Currículo Lattes: http://lattes.cnpq.br/9474013624820606. ORCID: https://orcid.org/0000-0001-8695-5980.E-mail: fvaznunes@gmail.com.

${ }^{2}$ Atualmente é professor de Estética, Filosofia e Teoria da Arte na Universidade Estadual do Paraná, em Curitiba, no Campus I (Escola de Belas-Artes do Paraná) e no Campus II (Faculdade de Artes do Paraná). Mestre em Filosofia pela UFPB e Doutor em Filosofia pela UFPR. É membro do Núcleo de Estudos Discursivos em Arte e Design (NEDAD), e do Núcleo de Artes Visuais (NAVIS). Link para o Currículo Lattes: http://lattes.cnpq.br/5690969862394264. ORCID: https://orcid.org/0000-0001-8009-0250. E-mail: andersonbogea@gmail.com.

${ }^{3}$ Atualmente é professor de História da Arte na Universidade Estadual do Paraná, Campus I (Escola de Música e Belas Artes do Paraná). Doutor em História pela Universidade Federal do Paraná (UFPR - 2015), Mestre em História pela Universidade Federal do Paraná (UFPR - 2008). É pesquisador vinculado ao Núcleo de Artes Visuais (NAVIS). Desenvolve pesquisas nas áreas de História com ênfase em História e Cinema, História da Arte, Ficção Policial e Crime. Link para o Currículo Lattes http://lattes.cnpq.br/3787622957343646. ORCID: https://orcid.org/0000-0002-5162-0264. Email: lcsereza@gmail.com
} 


\section{ART, PLAY AND LUDICITY: AN EMERGENT EXPERIENCE OF REMOTE TEACHING AND EXTENSION}

ABSTRACT: This article exposes some reflections about the relationship between art and games, which emerged from the emergencial remote teaching experience called Jogos, Poéticas, Estratégias e Gameficação - JPEG (Games, Poetics, Strategies and Gamification), part of Campo Remoto (Remote Field), the remote emergency activity developed by the Visual Arts courses from Universidade Estadual do Paraná - Campus Curitiba I, in 2020, motivated by the Covid-19 pandemics. From this experience, an university extension project called Fabrica Ludi was created, whose objective is to create games about the universe of the visual arts. Theories by Johann Huizinga (Homo ludens) and Roger Caillois (Man, play and games) about games were taken as starting points for the establishment of parallels with the philosophical concept of artistic autonomy and with the presence of the notion of game in the work of thinkers such as Friedrich Schiller and Ludwig Wittgenstein. With this theoretical framework, two games created by the Fabrica Ludi team, Giragira da arte (Art Merry-go-round) and The Artworld are presented and discussed, games in which the concepts of artworld by Arthur Danto and irony as a formative trope of historiography by Hayden White are employed to set up situations of playfulness.

Keywords: Art teaching; Games; Aesthetics.

\section{ARTE, JUEGO Y LUDICIDAD: UNA EXPERIENCIA EMERGENTE DE ENSEÑANZA Y EXTENSIÓN A DISTANCIA}

RESUMEN: Este artículo está dedicado a exponer algunas reflexiones sobre la relación entre arte y juego surgidas de la experiencia de la enseñanza remota de emergencia intitulada Juegos, Poéticas, Estrategias y Gamificación - JPEG, como parte del Campus Remoto, una actividad remota de emergencia desarrollada en el ámbito de los cursos de artes visuales de la Universidade Estadual do Paraná - Campus Curitiba I, en 2020, debido a la pandemia de Covid-19. De esta experiencia surgió un proyecto de extensión universitaria denominado Fabrica Ludi, cuyo objetivo es desarrollar juegos donde la temática sea el universo de las artes visuales. Tomando como punto de partida las reflexiones sobre juegos de Johann Huizinga (Homo ludens) y Roger Caillois (Los juegos y los hombres), se establecen paralelismos con el concepto filosófico de la autonomía del arte y con la presencia de la noción de juego de pensadores como Friedrich Schelling y Ludwig Wittgenstein. Sobre la base de este marco teórico, se presentan y discuten dos juegos creados por el equipo del proyecto Fabrica Ludi: The Artworld y Gira-gira da arte, en los que se muestran los conceptos de Arthur Danto sobre el "mundo del arte" y la ironía como tropo formativo de la historiografía de Hayden White. utilizado para establecer situaciones de ludicidad.

Palabras Clave: Enseñanza de arte; Juegos; Estética.

No decorrer do ano de 2020, o mundo viu-se surpreendido pela pandemia da Covid-19, que por conta da necessidade de se garantir a segurança sanitária das populações, surgiram também imensos desafios na área educacional. Neste contexto pandêmico, escolas e universidades foram obrigadas a desenvolver novos métodos e estratégias para dar algum tipo de continuidade às suas atividades. Várias instituições de ensino de arte se viram forçadas a tomar posição frente ao problema que há anos vinha assombrando o ensino superior, principalmente o público, a saber: a educação a distância. Algumas destas instituições se colocaram totalmente contra qualquer tipo de ação que minimamente remetesse a essa modalidade. A insegurança do momento aumentou o campo das incertezas, fazendo com que nenhuma das ações tomadas por essas instituições fossem simples e, nem mesmo, que seus resultados se apresentassem de maneira binária, em sentidos de acertos ou erros. Assim, as experiências vividas por alunos e professores e demais participantes destes processos pode (e deve) 
vir a ser alvo de pensamento e indagação do momento em que vivemos. Aos que buscaram os meios de manter os processos de ensino e aprendizagem, um dos desafios foi buscar alternativas possíveis para o desenvolvimento de atividades de ensino no formato remoto, que apresenta grandes deficiências por conta da natureza sensível do objeto artístico. Mesmo em uma época permeada por poéticas conceituais ou digitais menos afeitas à concepção da arte atrelada à obra como um objeto material, executado segundo certas técnicas mais ou menos tradicionais, as qualidades físicas e sensoriais dos suportes tão ligadas à história da arte - as tintas e telas da pintura, as matrizes e papéis da gravura, os vários materiais da escultura, para elencar apenas algumas das possibilidades, mais tradicionais, dentro das artes visuais - são ainda elementos valorizados dentro do registro artístico contemporâneo, apontando para a dimensão, eminentemente presencial da arte.

Nesse contexto, o curso de Bacharelado em Artes Visuais do Campus I da Universidade Estadual do Paraná - Escola de Música e Belas Artes do Paraná, situado em Curitiba/PR, foi drasticamente afetado pela pandemia. A resposta do colegiado foi propor um formato radicalmente diverso de ensino, abolindo as fronteiras entre as disciplinas e desenvolvendo um formato que contava com encontros semanais online síncronos, dois deles repetidos e ofertados aos dois diferentes turnos do curso e um terceiro ofertado em conjunto aos dois turnos, voltado para a apresentação de artistas e seus ateliês. Os encontros que eram ofertados aos dois turnos eram organizados como uma sequência de apresentações orais de diversos professores de disciplinas diferentes, e estruturados em torno de temas gerais ligados ao universo das artes visuais. Esta foi a estrutura básica do Campo Remoto, nome dado às atividades emergenciais de ensino remoto realizadas no segundo semestre de 2020 pelo Bacharelado em Artes Visuais da UNESPAR, desenvolvendo-se como um verdadeiro experimento de ensino artístico universitário. Nas apresentações dos professores, os limites entre as disciplinas foram abolidos, adotando-se, para a organização das apresentações orais, o termo "temporada" - em referência, algo irônica, às séries de sistemas televisivos de streaming - para cada conjunto de semanas que contavam com um tema comum. A última e mais longa dessas temporadas foi intitulada JPEG - Jogos, Poéticas, Estratégias e Gameficação, que se estendeu por seis semanas e que teve como tônica a exploração das relações entre arte e jogo em suas múltiplas acepções, usos e possibilidades. Este artigo se dedica a expor uma reflexão acerca das relações entre arte e jogo surgida dessa experiência de ensino e a relatar alguns dos desenvolvimentos criativos que foram gerados, da colaboração entre professores e estudantes, na criação de um projeto de extensão.

$\mathrm{O}$ que as artes visuais têm em comum com o universo dos jogos? O primeiro referencial teórico para esta aproximação foi a clássica obra do historiador holandês Johan Huizinga, Homo ludens, de 1938. Segundo Huizinga, nessa obra menos sistemática do que intuitiva e especulativa sobre o tema geral da ludicidade, o jogo é anterior à cultura, estando presente mesmo entre os animais: "O jogo é de fato mais antigo que a cultura, pois esta, mesmo em suas definições menos rigorosas, pressupõe sempre a sociedade humana; mas os animais não esperaram que os homens os iniciassem na atividade lúdica." (HUIZINGA, 2010, p. 3). Isso não implica, no entanto, que o jogo não esteja imbricado em uma atitude humana fundamental, a da criação de significados; para Huizinga, o jogo "[...] é uma função significante, isto é, encerra um determinado sentido. No jogo existe alguma coisa 'em jogo' que transcende as necessidades imediatas da vida e confere um sentido à ação. Todo jogo significa alguma coisa." (HUIZINGA, 2010, p. 3-4).

Em outro registro, Ludwig Wittgenstein também explora a relação entre jogo e significado, principalmente em sua fase menos ocupada com as línguas formais ou artificiais, como a lógica e a matemática, e mais interessada em entender os mecanismos de funcionamento das línguas naturais, quer dizer, as faladas em nosso cotidiano, como o inglês, o alemão e o português. Nas suas Investigações filosóficas, de 1953, na qual encontramos essa segunda via de Wittgenstein, o autor abre seu texto criticando o exclusivo foco ao aspecto designativo da linguagem dado pela tradição filosófica, e passa a considerar seus diversos usos (Cf. WITTGENSTEIN, 2009). Além da investigação sobre a linguagem e sua construção de significado, o que nos remete às Investigações 
de Wittgenstein é a noção de "jogos de linguagem" apresentada por ele nessa obra. No início da referida obra, o autor nos apresenta uma imagem sobre a linguagem a partir de uma descrição que Santo Agostinho faz da aquisição da linguagem em suas Confissões. Nisso que se convencionou chamar de imagem agostiniana da linguagem, toda palavra teria um significado, o qual seria o objeto designado pela palavra. Essa é uma apresentação primitiva do funcionamento da linguagem, e que acaba por ignorar que uma palavra possa ter mais de um significado atribuído a ela. Na sequência da sua argumentação, na seção 2, Wittgenstein sugere um contexto em que esse tipo de perspectiva agostiniana venha a funcionar, convidando-nos a imaginar um contexto primitivo de comunicação. Nesse exemplo, haveria um construtor $\mathrm{A}$ e um ajudante $\mathrm{B}$, construindo um prédio, e teriam à sua disposição alguns objetos como colunas, vigas, blocos e lajes para a construção, objetos que B deveria levar para A sempre que este gritasse alguma das palavras, previamente, estabelecidas: "coluna", "viga", "bloco", "laje". "A grita as palavras; - B traz a pedra que aprendeu a trazer ao ouvir esse grito. - Conceba isto como uma linguagem primitiva completa". (WITTGENSTEIN, 2009, p. 16, § 2).

Podemos imaginar também que todo o processo de uso de palavras em (2) [referindose aqui ao contexto apresentado na seção dois apresentado acima] seja um dos jogos por meio dos quais as crianças aprendem sua língua materna. Quero chamar esses jogos de "jogos de linguagem", e falar de uma linguagem primitiva às vezes como de um jogo de linguagem.

E poder-se-ia chamar também de jogos de linguagem os processos de denominação das pedras e de repetição da palavra pronunciada. Pense em certo uso que se faz das palavras em brincadeiras de roda.

Chamarei de "jogo de linguagem" também a totalidade formada pela linguagem e pelas atividades com as quais ela vem entrelaçada. (WITTGENSTEIN, 2009, p. 18$19, \S 7)$.

O uso das expressões nos diversos jogos de linguagem é composto por certos elementos que se encontram relacionados de modo intrínseco, isto é, o sentido de uma determinada expressão e a forma que essa expressão é proferida (a força imbuída). Assim, é no contexto de proferimento das expressões que seu significado pode e deve ser encontrado, ao invés de entendermos que as expressões têm significados fixos sob a perspectiva de uma rigidez semântica. Para Wittgenstein, o “[...] significado de uma palavra é seu uso na linguagem." (WITTGENSTEIN, 2009, p. 38, § 43). Nessa perspectiva, Wittgenstein afirma que podemos "[...] imaginar também que alguém tenha aprendido o jogo sem jamais aprender as regras, ou sem formulá-las”. (WITTGENSTEIN, p. 31, § 31). Em casos envolvendo jogos de linguagem, são seus contextos de uso que nos permitem "jogálos", e não necessariamente por meio da aprendizagem de suas regras. Atribuímos sentido às expressões pelo modo como as usamos. Como em um jogo como o xadrez, que se tomamos como analogia, percebemos que o indivíduo aprende um jogo como esse sem o recurso das regras diretamente, mas por meio da observação de uma partida. No caso do jogo Gira-gira da arte, que abordaremos adiante, as regras têm sua importância, de fato, mas é notório como muitas vezes é no jogar que que os participantes atribuem sentido aos movimentos no tabuleiro. "A expressão 'jogo de linguagem' deve salientar aqui que falar uma língua é parte de uma atividade ou de uma forma de vida". (WITTGENSTEIN, 2009, p. 27, § 23). Nesse sentido, devemos buscar o significado nas práticas de uma comunidade linguística, em contextos de sociabilidade, o que reitera a hipótese da linguagem como um modo de agirmos no mundo.

A partir das reflexões de Wittgenstein, percebemos a conexão entre as concepções de linguagem e jogo, e o jogo, ele mesmo, como uma forma de linguagem, e, portanto, como uma forma de vida que visa a construção de significados. Com a atribuição de uma dimensão significativa aos jogos realizada por Huizinga, vistos ao mesmo tempo como transcendentes em relação às "necessidades imediatas da vida", ou seja, desligados de funções diretamente utilitárias e funcionais, aprofundamos a analogia 
entre arte, jogo e linguagem, como "forma de vida" que possui uma dimensão de autonomia com relação à realidade prática. Pois, segundo o teórico holandês, o jogo

[...] se insinua como atividade temporária, que tem uma finalidade autônoma e se realiza tendo em vista uma satisfação que consiste nessa própria realização. É pelo menos assim que, em primeira instância, ele se nos apresenta como um intervalo em nossa vida cotidiana. (HUIZINGA, 2010, p. 12).

Esse caráter autônomo da ludicidade, de exceção com relação à vida cotidiana, comunica-se diretamente com um dos conceitos artísticos centrais desenvolvidos ao longo da modernidade: a noção da autonomia da obra de arte, a sua aparente inutilidade imediata diante das necessidades do dia-a-dia, e a construção, no objeto artístico, de uma ordem diversa daquela do que chamamos - algo ingenuamente, mas é assim que o chamamos - de "mundo real".

Aqui é inevitável compararmos o sentido de autonomia do jogo elaborado por Huizinga àquele que encontramos em Teoria da vanguarda, obra de Peter Bürger, e ao mesmo tempo com a noção de "desinteresse" como característica tão presente nas teorias do gosto do século XVIII, desde Anthony Ashley Cooper, terceiro conde de Shaftesbury, que introduz a noção em seu argumento sobre o prazer desinteressado tanto para o belo como para a virtude, em The moralist: a philosophical rhapsody, que compõe Characteristics of Men, Manners, Opinions, Times (1711), até a atribuição de Immanuel Kant do desinteresse ao juízo de gosto no final do século XVIII. (Cf. GUYER, 2008). Na contemporaneidade, identificamos ainda uma disputa em torno da atitude estética, em um embate entre autores como Edward Bullough e George Dickie quanto à pertinência de se sustentar o lugar dessa noção diante de uma experiência artística (Cf. DICKIE, The myth of aesthetic attitude, 1964). Tal noção ainda aparece como uma das características ligadas não apenas ao gosto, ao juízo de gosto e à experiência estética, mas também às belas-artes, como uma postura que demarca a especificidade destas em comparação às artes mecânicas, por exemplo (Cf. KRISTELLER, 2021). Quanto à noção de autonomia da arte, para Bürger, é um fenômeno da arte e da sociedade burguesa, que tem como característica fundamental o "descolamento da práxis vital", o distanciamento entre arte e vida, ao mesmo tempo que se funda em uma produção e recepção individuais da obra de arte:

Para evitar mal-entendidos, é preciso tornar a sublinhar com toda ênfase que "autonomia", nesse sentido, designa o status da arte na sociedade burguesa, o que, porém, não envolve ainda qualquer afirmação sobre o conteúdo da obra. Enquanto a instituição arte, por volta do final do século XVIII, é dada como inteiramente formada, o desenvolvimento dos conteúdos das obras está sujeito a uma dinâmica histórica cujo ponto final é atingido no esteticismo, quando a arte se transforma em conteúdo de si mesma. (BÜRGER, 2012, p. 96).

É notável como as concepções de Huizinga sobre o jogo se aproximam dessa tradição de defesa de autonomia da arte, visto que, para Huizinga, o jogo estabelece uma ordem de caráter circular, que implica na sua liberdade com relação à "confusão" da vida. Assim como a arte - dentro da perspectiva da sua autonomia -, o jogo é um "lugar" especial, que busca preservar-se das imperfeições mundanas:

Reina dentro do domínio do jogo uma ordem específica e absoluta. E aqui chegamos a sua outra característica, mais positiva ainda: ele cria a ordem e é ordem. Introduz na confusão da vida e na imperfeição do mundo uma perfeição temporária e limitada, exige uma ordem suprema e absoluta: a menor desobediência a esta "estraga o jogo", privando-o de seu caráter próprio e de todo e qualquer valor. (HUIZINGA, 2010, p. 13).

A posição de Huizinga, ainda que bastante utópica - desconsiderando, por exemplo, as complexas relações do esporte competitivo com o poder econômico e midiático, de forma que o teórico holandês considera que o esporte profissional implica na "perda de uma parte das características lúdicas mais puras" (HUIZINGA, 2010, p. 219) - estabelece um ponto de vista sobre o jogo que é profundamente fecundo em sua analogia com o universo artístico. Em um certo sentido, uma visita a um museu de 
arte é, precisamente, um "intervalo" em nossa vida cotidiana: é uma ocasião que transcende a vida real, do trabalho e das ocupações cotidianas, da política e da economia, mesmo que possa tomar o trabalho, o cotidiano, a política e a economia como temas; a arte institui a sua própria ordem, e cria, ela mesma, os seus próprios grupos e regras, bastante reais, mas que possuem uma lógica própria. Assim, a noção de desinteresse tão característica à filosofia moral e ao pensamento estético do século XVIII é muito influente na caracterização de Huizinga sobre o conceito de jogo, visto que sua finalidade "[...] é exterior aos interesses materiais imediatos e à satisfação individual das necessidades biológicas". (HUIZINGA, 2010, p. 12). Desse modo, uma das influências ao tipo de argumento construído por Huizinga acerca do jogo como um intervalo parece residir nas reflexões que Friedrich Schiller apresenta na Educação estética do homem: numa série de cartas (2017) - apesar de o mesmo Huizinga mencionar apenas uma vez, em nota no capítulo 10, o conceito de Spieltrieb schilleriano, distanciando-se do que define como um hipotético instinto lúdico (Cf. HUIZINGA, 2010, p. 187).

Apesar dessa distância marcada em relação a Schiller, é ainda interessante notar algumas confluências entre os dois autores. No que diz respeito às questões da vida cotidiana, por exemplo, e dado o contexto em que as 27 cartas são publicadas originalmente, em 1795, Schiller, de maneira ousada, reconhece o lugar do estético frente ao político, "[...] pois é na beleza que se vai à liberdade". (SCHILLER, 2017, p. 24). A crítica ao contexto histórico em que Schiller está inserido fica bem nítido na seguinte passagem: “A utilidade é o grande ídolo do tempo; quer ser servida por todas as forças e cultuada por todos os talentos. Nesta balança grosseira, o mérito espiritual da arte nada pesa, e ela, roubada de todo estímulo, desaparece do ruidoso mercado do século". (SCHILLER, 2017, p. 23). Claramente, há uma repulsa por parte do autor em relação ao tipo de preocupação que passou a ocupar as mentes das pessoas nessa sociedade burguesa em ascensão, e como a dimensão econômica passou a dominar esse contexto cultural. Em oposição à contemporaneidade europeia de Schiller, este opõe o passado grego:

Naqueles dias do belo despertar das forças espirituais, os sentidos e o espírito não tinham ainda domínios rigorosamente separados; a discórdia não havia incitado ainda a divisão belicosa e a demarcação das fronteiras. [...] Quão diferente é a situação entre nós outros modernos! Também entre nós se projetou a imagem da espécie, ampliada em suas partes, nos indivíduos - mas por fragmentos, não em combinações diferentes, de modo que, para reconstruir a totalidade da espécie, é preciso indagar, um a um, todos os indivíduos. [...].

Foi a própria cultura que abriu essa ferida na humanidade moderna. [...] $\mathrm{O}$ entendimento intuitivo e o especulativo dividiram-se com intenções belicosas em campos opostos, cujos limites passaram a vigiar com desconfiança e ciúme, e com a esfera à qual limitou sua atuação, cada um deu a si mesmo um senhor que não raro termina por oprimir as demais potencialidades. (SCHILLER, 2017, p. 35-36).

Essa cisão entre intuição e especulação, entre sentidos e espírito, que marca a Modernidade, segundo Schiller, se caracteriza como a oposição entre forças opostas: o impulso sensível e o impulso formal - o primeiro relacionado à existência física ou natureza sensível do ser humano e o segundo à sua existência absoluta ou natureza racional. (Cf. Cartas XII e XIII). Como superar essa fragmentação do indivíduo na Modernidade representada por essa oposição de impulsos? Schiller recorre ao jogo, inicialmente, como metáfora, ao afirmar que apesar de "[...] o exercício ginástico forme corpos atléticos, somente o jogo livre e regular dos membros desenvolve a beleza". (SCHILLER, 2017, p. 41). Em um movimento certamente inspirado no livre jogo das faculdades definido pela estética kantiana, Schiller lança mão de um terceiro impulso, em que tanto o sensível como o formal atuam juntos, o impulso lúdico (Spieltrieb). Este permite ultrapassar a dimensão da mera abstração da forma e da mera impressão da vida, a um só tempo, pois apenas “[...] quando sua forma vive em nossa sensibilidade e sua vida se forma em nosso entendimento o homem é forma viva,e este será sempre o caso quando o julgamos belo". (SCHILLER, 2017, p. 73). O caráter lúdico desse impulso se explica 
pelo fato de que "[...] o homem deve somente jogar com a beleza, e somente com a beleza deve jogar". (SCHILLER, 2017, p. 76). De modo que o ser humano só joga quando é ser humano em sentido pleno, e só é ser humano em sua plenitude quando joga, para além do significado dos jogos da vida cotidiana, mas como um ideal, equilibrando seus dois impulsos fundamentais. Nesse sentido, Schiller se distingue de Huizinga visto que este busca tratar dos jogos não em um sentido metafísico ou ulterior, mas em uma perspectiva do cotidiano, apesar de sustentar o jogo e o jogar como um intervalo no próprio cotidiano e uma ruptura com a lógica de mercado, utilitária e relativa ao trabalho. No entanto, retornando a Huizinga, percebe-se as aproximações entre os dois autores, com a veemente defesa do teórico holandês do caráter livre, vital e pleno do jogo:

Numa tentativa de resumir as características formais do jogo, poderíamos considerálo uma atividade livre, conscientemente tomada como "não séria" e exterior à vida habitual, mas ao mesmo tempo capaz de absorver o jogador de maneira intensa e total. É uma atividade desligada de todo e qualquer lucro, praticada dentro de limites espaciais e temporais próprios, segundo uma certa ordem e certas regras. Promove a formação de grupos sociais com tendência a rodearem-se de segredo e a sublinharem sua diferença em relação ao resto do mundo por meio de disfarces ou outros meios semelhantes. (HUIZINGA, 2010, p. 16).

Ainda que esta noção, comum ao jogo e à arte, de uma radical autonomia, de um desprezo pelo lucro imediato, seja francamente utópica, trata-se de uma utopia que, no caso da arte, é formativa da sua própria condição contemporânea a partir das conquistas modernas: uma das características centrais da Modernidade na arte é, precisamente, a busca radical da liberdade, da diferenciação com relação a valores exteriores; a luta das vanguardas do século XX foi, em grande parte, a afirmação radical da liberdade da arte. Ainda hoje, os artistas gozam de um status cultural ligado a uma noção vaga de diferenciação: não se censura ao artista - e muitas vezes, ao contrário, celebra-se - uma certa excentricidade no vestuário, nos penteados, no próprio comportamento; o "mundo da arte" é, para o bem ou para o mal, um mundo para iniciados, que possui as suas regras, os seus rituais, os seus sistemas de valores. Huizinga fala que o jogo institui um "círculo mágico": o local onde o jogo se desenrola assume uma certa sacralidade, pois a ordem que vige dentro dele é diversa daquela que ordena o mundo prático e cotidiano; o mundo da arte institui uma série de círculos mágicos, que são os ambientes do museu, da galeria de arte; um ateliê de artista - se é um artista com relevância social - possui ele também, essa aura, essa ambiência especial que o transforma em um local onde coisas extraordinárias podem acontecer.

Outro autor a se debruçar sobre os jogos, Roger Caillois já intuía a analogia entre a arte e os jogos, mesmo que a arte moderna tenha rompido com muitas das regras do fazer artístico tradicional. Uma das características marcantes da modernidade foi, precisamente, a constante superação, polêmica e muitas vezes agressiva, dos modelos do passado. Entre a arbitrariedade das normas artísticas, das convenções, e o desafio às regras do jogo, no entanto, o novo fazer artístico instituiu novas regras, e o jogo prossegue, ainda que transformado, como demonstra Caillois:

Em pintura, as leis da perspectiva são em grande parte convenções. Engendram hábitos que, no fim, fazem-nas parecer naturais. Para a música, as leis da harmonia; para a arte dos versos, as da prosódia e da métrica; qualquer outra imposição, unidade ou cânone para a escultura, a coreografia ou o teatro. Todas compõem da mesma forma legislações diferentes, mais ou menos explícitas e detalhadas, que ao mesmo tempo guiam e limitam o criador. São como as regras do jogo por ele jogado. Em contrapartida, engendram um estilo comum e reconhecível em que se reconciliam e se compensam a variedade do gosto, a provação da dificuldade técnica e os caprichos do gênio. Essas regras têm algo de arbitrário, e aquele que as considerar estranhas ou incômodas tem a autorização para recusá-las e pintar sem perspectivas, escrever sem rima nem cadência, compor fora dos acordos admitidos. Ao fazê-lo, não joga mais o jogo e contribui para destruí-lo, pois essas regras, como para o jogo, só 
existem na medida em que são respeitadas. Negá-las, todavia, é ao mesmo tempo esboçar os futuros critérios de uma nova excelência, de um outro jogo cujo código ainda vago se tornará por sua vez tirânico, domesticará a audácia e interditará novamente a fantasia sacrílega. (CAILLOIS, 2017, p. 22-23).

Note-se que Caillois, como Huizinga, também assume uma postura utópica com relação aos jogos e à ludicidade em geral, ainda que de forma diversa. Segundo Caillois (2017, p. 38), "[...] o campo do jogo é um espaço reservado, fechado, protegido, ou seja, um espaço puro". Para este autor, o universo da ludicidade "pura" é ameaçado pela corrupção que pode atingir todas as suas diferentes categorias de jogos, cada uma delas configurando-se como vícios ou desvios distintos. Os jogos oferecem um lugar seguro para a manifestação de instintos, com todas as suas dimensões perigosas, por vezes violentas e destrutivas; o seu extravasamento para o mundo real, e a contaminação decorrente geram consequências a ser evitadas.

Se o jogo consiste em fornecer a estes poderosos instintos uma satisfação formal, ideal, limitada, mantida distante da vida cotidiana, o que ocorre então quando toda convenção é rejeitada? Quando o universo do jogo não é mais estanque? Quando há contaminação com o mundo real, onde cada gesto acarreta consequências inelutáveis? [...] Uma vez que o império do instinto volta a ser absoluto, a tendência que conseguia abusar da atividade isolada, protegida e de alguma forma neutralizada do jogo propaga-se pela vida cotidiana e tende a subordiná-la tanto quanto possível às suas próprias exigências. (CAILLOIS, 2017, p. 88-89).

O paralelo com a questão da autonomia artística é bastante evidente: também o universo artístico foi - e, ainda é - vítima das angústias e medos decorrentes das relações perigosas, "contaminantes", entre a arte e a vida cotidiana, o "mundo real" fora dos museus e das galerias, que parecem ameaçar tanto a arte quanto, por vezes, o mundo ao qual ela se dirige. Assim como as utopias modernistas sofreram com a irrupção do "mundo real" no conflituoso e bélico contexto da primeira metade do século XX, com a ascensão dos fascismos e suas duas guerras mundiais, também o "círculo mágico" do jogo não é imune à realidade profana, bruta e material do poder econômico ou do conflito materializado em violência física. $\mathrm{E}$, aqui, Caillois parece mais próximo das preocupações que assolavam um romântico como Schiller, já no final do século XVIII, do que da utópica perspectiva de Huizinga.

Uma anedota histórica prova essa porosidade fatal dos "círculos mágicos" da arte e do jogo: em 1606, Caravaggio, um dos grandes artistas italianos da época, matou um jovem, supostamente em meio a uma briga por conta de uma dívida de jogo (Cf. LONGHI, 2012, p. 108); o crime teve profundas consequências sobre a vida do artista, obrigado a fugir de Roma, assim como sobre a sua obra. Essa porosidade do "mundo da arte" com relação ao mundo real, entretanto não compromete a validade, nem a fecundidade, das analogias entre arte e jogo: pelo contrário, aponta para mais um elemento em comum entre estes dois universos que buscam estabelecer as suas próprias regras, criar os seus próprios mundos autônomos em meio à realidade, transportando espectadores e jogadores para suas próprias realidades temporárias que não deixam, no entanto, de ter suas profundas e inevitáveis relações de troca e contaminação com a realidade.

Foi partir dessas premissas iniciais que, na temporada JPEG do Campo Remoto, foram abordados temas como a própria presença do jogo como elemento figurado na arte, o uso da metáfora do jogo na estética kantiana - a contemplação estética e o "livre jogo" das faculdades - e na filosofia de Wittgenstein, com sua noção de "jogo de linguagem", além de suas extensões e influências sobre a arte conceitual. Investigou-se ainda os jogos eletrônicos como suporte artístico, a presença da estratégia como elemento conformador do mundo artístico, da carreira e do acesso a meios de divulgação da arte, como editais e certames, assim como o jogo de gêneros no transformismo drag, e a construção de personas ficcionais como móvel poético na arte contemporânea - apenas para elencar alguns dos diferentes assuntos que foram explorados ao longo das seis semanas de duração do JPEG no final de 2020 .. 
Um dos aspectos que diferenciou a temporada JPEG do conjunto das ações do Campo Remoto foi a maior colaboração dos estudantes nas apresentações orais, antes limitada a comunicações de pesquisas realizadas no âmbito do Programa de Iniciação Científica da UNESPAR. Nessa última temporada do Campo Remoto, alguns estudantes foram convidados a realizar apresentações orais mais longas, ligadas tanto às suas pesquisas mais formais como também aos seus interesses e à sua própria atuação artística. Instigados por esse clima de colaboração, alguns professores e alunos, em diálogos informais via WhatsApp, deram início à criação colaborativa de jogos inspirados no universo artístico, em um primeiro momento de forma totalmente informal e desvinculada de qualquer articulação oficial com a instituição.

Nasceu, assim, a ideia de um jogo de RPG (role playing game) intitulado The Artworld, que simula um universo ficcional ligado ao mundo da arte, em que diferentes temporalidades são colocadas em contato. O próprio título indica a referência - crítica e irônica, no entanto - ao artigo de Arthur Danto, "The artworld", de 1964, em que o teórico estadunidense defende uma definição da arte baseada na existência de uma atmosfera de teoria artística e um conhecimento de história da arte que justifica e, em última análise, torna possível, a existência do objeto artístico enquanto tal. A argumentação de Danto, hoje bastante conhecida nos meios acadêmicos, toma como exemplo as Brillo Boxes de Andy Warhol (1964) - em quase tudo indistinguíveis das caixas de esponjas de aço reais, encontradas no estoque de um supermercado - , indagando-se sobre o que faz delas "arte", e portanto diferentes do mero produto industrializado e desprovido, a princípio, de qualquer valor artístico.

O que, afinal de contas, faz a diferença entre uma caixa de Brillo e uma obra de arte consistente de uma caixa de Brillo é uma certa teoria da arte. É a teoria que a recebe no mundo da arte e a impede de recair na condição do objeto real que ela é (num sentido de é diferente do da identificação artística). É claro que, sem a teoria, é improvável que alguém veja isso como arte e, a fim de vê-lo como parte do mundo da arte, a pessoa deve dominar uma boa dose de teoria artística, assim como uma quantia considerável da história da recente pintura nova-iorquina. Isso poderia não ter sido arte cinqüenta anos atrás. Mas, então, não poderia ter havido, se tudo permanece igual, seguro de vôos na Idade Média ou borrachas para máquinas de escrever etruscas. $\mathrm{O}$ mundo tem que estar pronto para certas coisas - o mundo da arte não menos do que o real. É o papel das teorias artísticas, hoje como sempre, tornar o mundo da arte e a própria arte possíveis. (DANTO, 2006, p. 22).

A referência irônica a Danto e à sua teoria foi empregada, então, como título em uma proposta de um role playing game, no qual as temporalidades do futuro e do passado são colocadas em choque. Todo RPG parte de uma premissa ficcional que estabelece um mundo paralelo, com suas próprias regras, seus agentes e as condições às quais eles estão submetidos; a premissa do jogo The Artworld é a seguinte:

\section{Documenta de Kassel, 2025.}

O coletivo internacional de arte-ciência Ilynx Intl. propõe o trabalho artístico mais inovador de todos os tempos: o Time Warp, um portal temporal que estabelece uma ponte higgs-mesoniana entre a Berlim de 2025 e a Nova Iorque de 1970. Vários artistas, críticos de arte, curadores, colecionadores e outras personalidades do mundo artístico passam a viajar no tempo. A obra altera radicalmente a estrutura do continuum espaço-temporal e transforma os agentes do mundo artístico em uma nova elite internacional planetária. A economia mundial passa a ser dominada pela dinâmica do campo artístico, pela especulação no mercado de arte e pela loucura das grandes exposições: o planeta Terra torna-se viciado em arte, para sua alegria ou para seu infortúnio. 
Surge assim THE ARTWORLD, uma realidade alternativa que envolve duas épocas - 1970 e 2025 - e três centros artísticos mundiais: Nova Iorque, Berlim e São Paulo. Seus personagens estão ligados ao mundo pós-pandêmico de 2025 e à efervescência artística da década de 1970, e suas realidades profundamente alteradas envolvem transições no tempo, viagens internacionais, exposições, mercados de arte, competição por poder e influência e as diferentes ideologias, vertentes artísticas e teóricas em embate.

A nova realidade criada pelo Time Warp, no entanto, gera estranhas e perigosas consequências. Aqueles que viajam no tempo sofrem profundas alterações na sua estrutura quântica, que os dota de bizarras características - o que alguns chamam de poderes, outros chamam de maldição. Habilidades telepáticas, hiper-audição, memória fotográfica, capacidades pré-cognitivas e telecinese voluntária ou involuntária são algumas dessas habilidades, que levam seus possuidores à loucura e à ruína, ou ao sucesso e fortuna. Os viajantes do Time Warp também se veem jogados em uma realidade na qual estão completamente despossuídos: no passado ou no futuro relativo às suas épocas de origem, após uma relativa fama inicial, são pobres, frequentemente deprimidos ou perturbados psicologicamente, e contam apenas com sua astúcia e suas habilidades, frequentemente traiçoeiras, para alcançar algum sucesso e posição em THE ARTWORLD.

Entre artistas, críticos, curadores, colecionadores, galeristas bem estabelecidos em suas épocas originais - e enriquecidos a níveis estratosféricos pelo recente prestígio alcançado pelo universo artístico planetário por conta do Time Warp - os viajantes do tempo, chamados pejorativamente de warps, lutam para sobreviver, criar e alcançar posições de destaque.

A dinâmica desse mundo artístico que domina economicamente o mundo, porém, não está imune ao processo histórico. Fatos extraordinários irrompem nesse universo bi-temporal: guerras são iniciadas; governos democráticos são derrubados e dão lugar a ditaduras ferrenhas, ou vice-versa; desastres climáticos afetam o futuro e o passado, e pandemias viajam no tempo. Nenhuma posição é estável, e nada é previsível em THE ARTWORLD. (NUNES et al., 2020, p. 1-2).

O RPG, assim, toma o termo cunhado por Danto, e portanto ligado à sua definição teórica da arte, para subvertê-la em meio a um jogo que é, ao mesmo tempo, um experimento artístico em desenvolvimento, envolvendo aspectos teóricos mas, ao mesmo tempo, ficcionais e poéticos. A postura irônica diante da noção de Danto do artworld implica em utilizar como referência a sua definição de arte baseada na teoria, e na teoria historicamente determinada, para denominar uma construção ficcional em que a história é submetida a uma situação paradoxal que é, ao mesmo tempo, um clichê ficcional: o da viagem no tempo. O jogo é, assim, o processo de imaginar o que aconteceria se artistas de um futuro próximo pudessem se deslocar temporalmente para o passado, para uma época que, dentro da história da arte, foi crucial para a formação de vários dos conceitos que são hoje de uso corrente por várias vertentes da arte contemporânea, próximo, inclusive, da própria época em que foi escrito o texto de Danto.

Desenvolvido ao longo da temporada JPEG, o RPG The Artworld é ainda um protótipo, demandando testes de funcionamento para que seja refinado e jogado por um público mais amplo. No início de 2021, parte do grupo envolvido na criação deste protótipo passou a desenvolver uma segunda proposta de jogo ligado ao universo artístico, buscando criar algo mais simples e que exigisse um tempo menor de elaboração e testagem. Surgiu, assim, um segundo jogo - na verdade, o primeiro a ser efetivamente testado em situações práticas de jogo e jogado com um público mais amplo chamado Gira-gira da arte, inspirado em jogos clássicos de tabuleiro. 


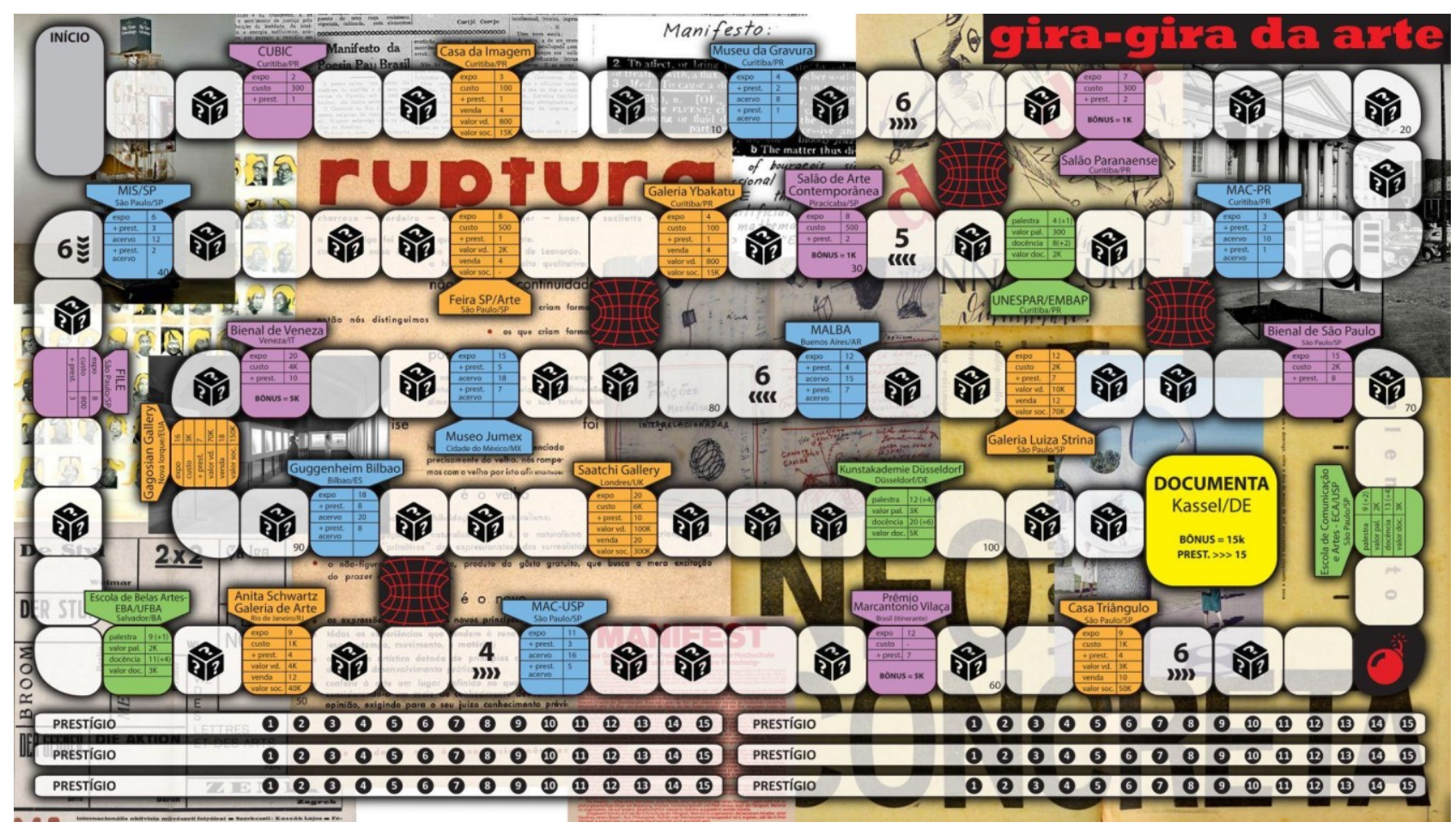

Tabuleiro do Gira-gira da arte. Design: Fabricio Vaz Nunes

No Gira-gira da arte, os jogadores são representados por peões coloridos que avançam pelas casas do tabuleiro, ingressando em instituições do universo artístico como museus, galerias, exposições e escolas de arte. Nestes locais, os jogadores devem realizar exposições, vender obras, proferir palestras e até mesmo exercer atividades docentes: em cada uma destas atividades, eles são recompensados com ganhos monetários e de prestígio, representado por pontos que são acumulados e indicados em marcadores na parte inferior do tabuleiro. Os jogadores também contam com cartas de influência sobre as instituições, que oferecem facilidades para aquele que a possui ou permitem que influa sobre as ações dos outros jogadores, tornando as suas ações mais fáceis ou mais difíceis. O jogo é jogado em uma plataforma online, devido às circunstâncias atuais do cenário pandêmico. Foi a partir do desenvolvimento do Gira-gira da arte que surgiu a ideia de transformar esta prática de criação e disseminação de jogos ligados ao universo artístico em um projeto de extensão universitária que recebeu o nome Fabrica Ludi, com o objetivo de divulgar esses jogos a um público mais amplo, dentro de uma estrutura institucional.

Assim como em The Artworld, o Gira-gira da arte é marcado pela representação irônica e ácida da realidade do mundo da arte. Neste jogo, não há nenhuma referência a obras de arte, vertentes ou estilos artísticos - aspectos que são previstos no protótipo de The Artworld - mas, simplesmente valores monetários e valores numéricos de prestígio. O que importa, portanto, é a sorte dos participantes, que devem rolar dados para cumprir as ações necessárias para obter dinheiro e prestígio, e a sua capacidade de estabelecer alianças ou agir de forma a impedir os demais jogadores de cumprirem seus objetivos. O tabuleiro é repleto, também, de casas com eventos aleatórios (indicadas pelo ícone do dado com interrogações), que devem ser cumpridos pelos jogadores quando caem em uma casa em que estes eventos são indicados através de um sorteio online que simula a retirada de uma carta em um jogo presencial. Estes eventos incluem aspectos escusos das relações entre os vários agentes no mundo da arte, como curadores, críticos e artistas, assim como acidentes de trabalho, incidentes legais e da vida sócio-econômica, e que afetam os artistas de variadas maneiras. Dentre o conjunto desses eventos aleatórios, alguns exemplos servem para demonstrar o caráter irônico, e às vezes intencionalmente vulgar, do que pode suceder aos jogadores: 
Você xavecou a curadora. Perca 1 ponto de prestígio.

O curador se apaixonou por você. Ganhe 1 ponto de prestígio.

$\mathrm{O}$ curador se apaixonou por você. Ele é um babaca que todos odeiam. Perca 1 ponto de prestígio.

Você plagiou uma obra. Ninguém percebeu. Ganhe 1 ponto de prestígio.

Você teve uma lesão produzindo uma obra. Fique uma rodada sem jogar.

Você bebeu na vernissage e queimou o filme. Perca 1 ponto de prestígio.

Você bebeu na vernissage e queimou o filme. Ganhe 1 ponto de prestígio.

Você falou mal de uma obra sem saber que o artista estava na roda. Perca 1 ponto de prestígio.

O curador quer te comer. Ganhe 1 ponto de prestígio.

A curadora quer te comer. Ganhe 1 ponto de prestígio.

Você recebeu uma crítica negativa. Perca 1 ponto de prestígio.

Um grande colecionador comprou uma obra sua. Ele é neonazista. Ganhe \$ 3000 e perca 2 pontos de prestígio.

Você surtou e desistiu do doutorado. Volte 4 casas.

Alguém plagiou a sua obra. Você processou e ganhou. Ganhe $\$ 5000$ e 1 ponto de prestígio.

Alguém plagiou a sua obra. Você processou e perdeu. Pague $\$ 3000$ e perca 1 ponto de prestígio.

Você fez um comentário racista numa rede social e foi cancelado. Perca 2 pontos de prestígio.

Você fez amigos e influenciou pessoas. Sorteie uma carta de influência. (como fazer a referência?)

CRISE ECONÔMICA MUNDIAL. Todos os valores recebidos são reduzidos pela metade por três rodadas.

Você foi vender a sua arte na praia. Ganhe $\$ 500$ e fique uma rodada sem jogar. (NUNES et al., 2021, p. 13-14).

As experiências de criação de jogos, assim como a prática do jogar, formatadas como o projeto de extensão universitária Fabrica Ludi, passaram então a ser pensadas também na sua dimensão educativa e de divulgação. No desenvolvimento do jogo Gira-gira da arte, foi curioso como vários dos raciocínios desenvolvidos por Wittgenstein em suas Investigações filosóficas se concretizaram: como mencionamos antes, foi, precisamente, na prática do jogar que não apenas as regras eram aprendidas, tanto pelos membros da equipe quanto por participantes externos, como também diferentes significados eram atribuídos aos movimentos dos peões e às ações dos jogadores. Em meio aos diálogos estabelecidos ao longo do jogo, permeados pela competição bem-humorada, por chistes, vanglórias pelos sucessos e lamentos pelos insucessos, sempre em tom de brincadeira, surgiram narrativas, como atribuir determinadas conquistas ao bom ou mau caráter dos artistas-jogadores, ou atribuir azares contínuos a ações eticamente questionáveis, como o plágio ou comentários preconceituosos. Viagens fracassadas e tentativas frustradas se tornam inspiração para a comparação com artistas reais ou imaginários, em seu embate pela obtenção de prestígio e dinheiro, marcado pela competição mas também, muitas vezes, pela colaboração solidária dos artistas-jogadores. Assim, como afirmava Huizinga, nesse jogo que estabelece o seu "círculo mágico", (supostamente) desprovido de consequências imediatas sobre a vida real, discute-se o quanto elementos não 
diretamente artísticos - como a atração entre artistas e curadores, o consumo excessivo de álcool em uma vernissage e comentários ofensivos em redes sociais - podem ter influência direta sobre a arte e seus agentes, proporcionando questionamentos sobre os limites da autonomia da arte.

\section{Considerações finais}

O desenvolvimento de estratégias de ensino por meio de jogos, elaborados de modo coletivo pelo grupo envolvido no projeto Fabrica Ludi desde o final de 2020 criou, também, uma relação incidental com processo e ensino de história da arte, um dos saberes-base para confecção de tais produtos. A analogia entre arte e jogo, desenvolvida na temporada Jogos, Poéticas, Estratégias e Gameficação JPEG do Campo Remoto e expandida para o projeto de extensão Fabrica Ludi, tem sido capaz, assim, de proporcionar um meio de discussão e divulgação do conhecimento e da reflexão sobre o fenômeno artístico. A analogia é, no fundo, uma metáfora: uma figura de linguagem que serve, aqui, como uma estratégia metódica, um modo de abordagem do objeto de estudo. Empregando um método que é, no fundo, poético - pois a metáfora é, entre outras coisas, um tropo literário, ou seja, um desvio do uso convencional da linguagem -, esses experimentos que unem arte e jogo trazem à tona as reflexões de Hayden White sobre a natureza do discurso histórico. Para o filósofo e historiador estadunidense, a história, enquanto campo do saber, se estrutura a partir de modelos literários conhecidos, na medida em que o historiador não se limita a elencar os fatos do passado, mas, ao descrevê-los discursivamente, emprega determinados modelos derivados da ficção:

[...] as narrativas históricas são não apenas modelos de acontecimentos e processos passados, mas também afirmações metafóricas que sugerem uma relação de similitude entre esses acontecimentos e processos e os tipos de estória que convencionalmente utilizamos para conferir aos acontecimentos passados de nossas vidas significados culturalmente sancionados. (WHITE, 2014, p. 105).

Transportando a analogia de White entre a literatura e a história para a nossa analogia entre a arte e os jogos, temos a reflexão sobre o fenômeno artístico sendo desenvolvido através de um elemento "culturalmente sancionado", como jogos de tabuleiro e RPGs, entendidos como estruturas simbólicas através das quais o universo artístico é representado. Em outras palavras, os jogos que foram desenvolvidos como desdobramentos da temporada JPEG do Campo Remoto são representações e reflexões sobre o mundo da arte, realizadas por meio de lógicas culturalmente reconhecíveis: a dos jogos de tabuleiro e a dos role playing games, esta última incluindo, ainda, um clichê narrativo, o da viagem no tempo. Ambos os jogos estabelecem, assim, narrativas próprias; eles criam as suas próprias estórias, que, por sua própria estrutura narrativa, estão em íntima relação com a História como prática discursiva acerca do real. Voltando a White:

Corretamente entendidas, as histórias nunca devem ser lidas como signos inequívocos dos acontecimentos que relatam, mas antes como estruturas simbólicas, metáforas de longo alcance, que "comparam" os acontecimentos nelas expostos a alguma forma com que já estamos familiarizados em nossa cultura literária. (WHITE, 2014, p. 108).

Os jogos desenvolvidos estabelecem também comparações e metáforas com a história da arte recente, dentro de uma cultura familiar - a própria cultura dos jogos, a qual carrega elementos culturais e experiências que permitem a clivagem entre diferentes pretéritos e acontecimentos. Nesse sentido, tivemos um resultado de pesquisa, ou ao menos um insight, percebido após o desenvolvimento das atividades. Tais processos em forma de jogos tensionaram os modos de apresentação da narrativa histórica da arte, no sentido de colocar outros focos, percepções e poiesis nos sistemas de imaginação históricas. Assim como houve outras formulações de temporalidades em relação ao texto produzido, diferente das narrativas acadêmicas, aquilo que Hayden White viria a chamar de "passado histórico", 
os jogos necessariamente tiveram de passar por negociações, apropriações e construções de outra ordem. A percepção do passado regulado pelas fortes linhas de pensamento disciplinares ainda estava lá, mas adentramos nos campos em que a memória, imaginários sociais e toda uma gama de dispositivos da ficção permitem a reconfiguração dos passados. Em certo sentido, os jogos permitiram dialogar com o que Hayden White chamou de "passado prático":

[...] uma versão do pretérito que a maioria de nós leva em nossas mentes e utiliza na realização de tarefas diárias nas quais somos compelidos a julgar situações, resolver problemas, tomar decisões e, mais importante, talvez, responder às consequências das decisões feitas tanto por nós e para nós por essas instituições das quais somos, mais ou menos, membros conscientes. (WHITE, 2018, p. 16).

O passado prático, então, é aquele veiculado em narrativas e historiografias sem controles disciplinares ou, ao menos, distante do controle das disciplinas históricas. Entretanto, ele não é um saber neutro; ao contrário, tem um potente poder de significação e certamente acessa muito mais pessoas que as formas disciplinares. Essa tipologização do pretérito atravessa diversos produtos culturais e quase sempre é vista como desdém pelos operadores disciplinares. Para alguns autores, como Robert Rosenstone, trata-se de uma historiografia concorrencial, com a qual os historiadores são obrigados a conviver, e que na maior parte do tempo é a responsável por organizar o pensamento histórico cotidiano (ROSENSTONE, 2010, p. 15). Embora exista um sem-número de problemas nas formas de registro do passado prático, como a falta de rigor com a documentação ou a ausência de um problema que informe o processo narrativo, ou ainda a naturalização constante de certas evidências como "fatos históricos", ainda assim vale destacar que a democratização do saber histórico dificilmente ocorre sem que haja alguma negociação ou interação entre o passado histórico e o prático. Nesse sentido, narrativas históricas veiculadas em produtos culturais, artísticos e sensíveis podem vir a romper o problema das barreiras criadas pela cientificização dos campos das narrativas históricas.

Afinal, a escritura da história, a operação historiográfica, comumente desenvolvida nos espaços acadêmicos, parece manter um apego às formas de escrita idealizadas ou marcadas pela tensão do abandono da retórica, ainda no século XIX, que permitiu a institucionalização da história científica recusando, ou ao menos contendo, as capacidades poéticas da escrita sobre o passado. Curiosamente, essa ação ainda guardava grande conexão com modos de registro literários, e na verdade o romance do século XIX foi um campo profícuo de modelagens da escrita histórica. Entre as ferramentas do legado romanesco temos o uso de figuras de linguagem, construção de personagens e recortes configurados dentro dos tropos linguísticos típicos da literatura da modernidade. Em certa medida, tais presenças perduram até hoje, nos trabalhos mais "avançados" de vários historiadores que são referência em diversas subáreas.

A cientificização e os modos de escrita criaram um problema ao "passado histórico", mantendo-o em grande parte do tempo desligado do mundo cotidiano, da vida da maior parte das pessoas. White foi uma das primeiras vozes a evidenciar esse problema, em uma das obras historiográficas mais importantes do século XX, Meta-história: A imaginação histórica do século XIX, de 1973. Neste livro, o autor identificou a presença de tropos literários na escrita de historiadores e filósofos da história do longo século da modernidade, e como um dos desdobramentos dessa pesquisa surge a percepção de que as artes do século XIX tiveram um papel ímpar no processo de composição da escrita da história; contudo, o mesmo não ocorreu em relação às renovações no mundo da arte através do predomínio dos modernismos do século XX. Para White, as escritas de modernistas como Conrad, Proust, Joyce, Eliot, Pound, Woolf, Kafka, Stein, Gide - aos quais poderíamos somar a arte visual de Picasso, Duchamp, Cézanne e tantos outros - foram desassociadas do discurso histórico, mesmo que hoje observemos que podiam ter sido incorporadas pelos diferentes modos de discursos das narrativas históricas, causando um desligamento entre as artes da primeira metade do século XX e a escritura das diversas narrativas do passado histórico. 
Tudo isso pode ser verdade, contanto que se perceba que a "história" da qual os modernistas estavam fugindo não era o mundo que eles encontravam na vida cotidiana, mas aquela versão fantasmagórica do passado construída pelos historiadores profissionais, aquele "passado histórico" elaborado por eles para esvaziar o pretérito de sua utilidade "prática". (WHITE, 2018, p. 19).

Para White, portanto, a história é sempre uma interpretação do passado (WHITE, 2014, p. 89), que implica, entre outras coisas, em determinadas estratégias narrativas que podem ou não estar ligadas às conquistas expressivas de outros campos culturais, estabelecendo-se sobre bases linguísticas que White crê ser possível constatar em todos os campos de estudo não-reduzidos ao status de ciência, que operam tropologicamente para estabelecer relações entre os elementos estudados (WHITE, 2014, p. 91). Como aventa o próprio autor estadunidense, o raciocínio pode ser estendido para as diversas teorias que tratam do fenômeno artístico: elas são diferentes estruturas simbólicas ligadas a saberes pré-constituídos - a filosofia, a sociologia, a história -, que buscam interpretar um objeto de estudo específico, empregando determinadas estratégias narrativas e estruturas linguísticas. Nesse sentido, o jogo é uma outra instância previamente existente que permite uma abordagem muito particular do fenômeno artístico, ele mesmo com as suas próprias estruturas lógicas e de linguagem. $\mathrm{O}$ emprego dos jogos como uma ferramenta de investigação da arte e dos modos como narramos a sua historicidade - em especial, da arte contemporânea - estabelece-se como uma metáfora cognitiva e reflexiva, que, empregando uma linguagem conhecida da maioria das pessoas desde a infância - a linguagem dos jogos -, torna-se capaz de proporcionar uma investigação de aspectos pertinentes do fazer artístico. Trata-se, portanto, de produção de conhecimento, mas de um conhecimento que é decididamente marcado pela dimensão da imaginação e da ficção. Como demonstram as pesquisadoras Silvia Español e Diana Pérez (2015), em seu estudo sobre as relações entre as artes e os jogos pela perspectiva da psicologia do desenvolvimento, a imaginação é fundamental para o conhecimento, e daí a importância dos jogos simbólicos para a cognição, assim como para a arte:

\begin{abstract}
A chave da imaginação é trazer para o aqui e agora o que não existe: o passado (experiência, memória), o futuro / possível (expectativa), o contrafactual (o impossível). A chave para a imaginação, então, é o contraste: entre o aqui e agora e o que não é aqui e agora. Assim como não há imaginação sem realidade, não há realidade sem imaginação, no sentido de que sem imaginação só há o solipsismo do instante, não há conceitos, não posso sair do aqui e agora puramente sensorial. É por isso que o jogo simbólico é tão crucial no desenvolvimento das capacidades representacionais / cognitivas humanas: um objeto físico que é, em vez de outra coisa, marca um contraste entre o que está aqui e o que não está presente a que se refere. E este não-presente pode ser tanto algo literal quanto não-literal. (ESPAÑOL; PÉREZ, 2015, p. 36. Tradução nossa.). ${ }^{4}$
\end{abstract}

O uso imaginativo da linguagem na construção do conhecimento, análogo aos jogos simbólicos referidos por Español e Pérez, implica, segundo White, no emprego de diferentes tropos, ou seja, "desvios" da linguagem comum. Os tropos predominantes na história seriam, segundo ele, a metáfora, a metonímia, a sinédoque e a ironia (WHITE, 2014, P. 91). Dentre estes tropos - estes "jogos de linguagem", para usar a expressão de Wittgenstein - o que mais nos interessa é a ironia, para White o mais problemático:

\footnotetext{
4 “La clave de la imaginación es traer al aquí y ahora lo que no está: lo pasado (experiencia, memoria), lo futuro/posible (expectativa), lo contrafáctico (lo imposible). La clave de la imaginación es, entonces, el contraste: entre el aquí y ahora y lo que no está aquí y ahora. Así como no hay imaginación sin realidad, no hay realidad sin imaginación, en el sentido de que sin imaginación sólo hay solipsismo del instante, no hay conceptos, no puedo salir del aquí y ahora puramente sensorial. Por eso el juego simbólico es tan crucial en el desarrollo de las capacidades representacionales/cognitivas humanas: un objeto físico que está en lugar de otra cosa, marca un contraste entre lo que está aquí y aquello no-presente a lo que remite. Y esto no-presente, puede ser tanto algo literal como no-literal."
} 
[...] a ironia sanciona a afirmação ambígua e possivelmente até mesmo a ambivalente. É um tipo de metáfora, mas um tipo que sinaliza sub-repticiamente uma negação da asserção de similitude ou diferença contida no sentido literal da proposição, ou pelo menos lhe dá uma qualificação decisiva. [...] O que está implícito aqui é um tipo de atitude para com o próprio conhecimento que é implicitamente crítico de todas as formas de identificação, redução ou integração metafóricas dos fenômenos. Em resumo, a ironia é a estratégia linguística que fundamenta e sanciona o ceticismo como tática explicatória, a sátira como modo de urdidura do enredo, e o agnosticismo ou o cinismo como postura moral. (WHITE, 2014, p. 93).

Mas, já em Meta-história, tal viés de pesquisa começava a dar sinais de transformações, principalmente no capítulo dedicado a Jacob Burckhardt, no qual White trabalha noções como a de realismo em relação à sátira nos textos do historiador da arte suíço; mais tarde, no mesmo livro, seria Benedetto Croce que ofereceria "a defesa filosófica da história no modo irônico" (WHITE, 2008, 383), título dado ao último capítulo do livro, estabelecendo a ironia como uma potente fórmula da imaginação histórica. É curioso que Burckhardt e Croce tenham sido os autores que tenham levado White a repensar as funções do tropo da ironia, uma vez que estes dois autores clássicos tiveram um papel central na história da arte: o suíço de maneira direta e o italiano compondo as bases para formação de uma escola de história da arte na Itália do século XX. Mais notável ainda é o fato de que é por meio do tropo da ironia que White desenvolve toda uma relação entre o pós-modernismo e as "metaficções históricas" (tipos de narrativas que constroem laços entre o mundo da ficção e formas de pensamento historiográficos não-regulados pelas disciplinas históricas), em seu próprio trabalho, abrindo frentes para se pensar a construção do passado prático. No contexto do projeto Fabrica Ludi, a ironia forneceu uma base operacional, mais do que uma base teórica, para o trabalho com dispositivos culturais e sensíveis que veiculam discursos históricos, como o caso dos jogos desenvolvidos durante um período de emergência e que, talvez, fossem apenas peças criadas para aproximar uma comunidade que vivia tempos de insegurança. Talvez a insegurança da pandemia tenha nos conduzido a questionar mais que o presente insólito dos anos de confinamento, mas também a própria "natureza" de nossas experiências acadêmicas, históricas e subjetivas.

Em jogos como The Artworld e Gira-gira da arte, o universo artístico real é representado, precisamente, por meio do registro da ironia, estabelecendo um jogo simbólico em que os significados não são fixos ou unívocos, mas estão sujeitos a uma fundamental ambiguidade representativa. Assim, ao abordar o universo artístico através de jogos simbólicos, o conhecimento que vem sendo gerado por essas experiências tem dois aspectos fundamentais, que estão diretamente ligados à própria natureza do jogo: o primeiro deles é a ludicidade, o prazer da brincadeira e do jogar, aspectos tão necessários nestes tempos trágicos de pandemia, marcados pelo medo e pela incerteza. O segundo deles é a ironia, ela mesma um tropo da linguagem, um desvio dos significados que pode, ao afirmar, dizer o seu contrário, e ao fazer de conta, realizar questionamentos e propor constatações sobre o mundo real. Quer dizer, ironia que nos permite construir significados diversos, fundamentalmente, através de um processo de cooperação entre os interlocutores - como no próprio jogo e na cooperação entre seus jogadores, visto que para que um gesto irônico seja bem-sucedido é essencial que aquele que recebe a ironia tenha a sagacidade de complementar o sentido da expressão irônica entregue por aquele que a realiza, assim como na metáfora, na piada e, talvez, também na arte. 


\section{Referências}

BÜRGER, P. Teoria da vanguarda. Tradução: José Pedro Antunes. São Paulo: Cosac \& Naify, 2012. CAILLOIS, R. Os jogos e os homens: a máscara e a vertigem. Tradução: Maria Ferreira. Petrópolis, RJ: Vozes, 2017.

DANTO, A. O mundo da arte. Tradução: Rodrigo Duarte. Artefilosofia, Ouro Preto, n. 1, p. 13-25, jul. 2006.

DICKIE, G. The myth of aesthetic attitude. American Philosophical Quarterly, Champaign, IL, vol. 1, n. 1, p. 56-65, jan. 1964.

ESPAÑOL, S.; PÉREZ, D. Los juegos, los contrastes y las artes. Boletín de Estética, San Martín, no. 33, ano XI, primavera 2015.

GUYER, P. As origens da estética moderna: 1711-35. In: KIVY, Peter (org.). Estética: fundamentos e questões de filosofia da arte. Tradução: Euclides Luiz Calloni. São Paulo: Paulus, 2008. p. 27-61.

HUIZINGA, J. Homo ludens: o jogo como elemento da cultura. Tradução: João Paulo Monteiro. São Paulo: Perspectiva, 2010.

KRISTELLER, P. O. O sistema moderno das artes: um estudo em história da estética. I. Tradução: Anderson Bogéa. Artefilosofia, Revista do Programa de Pós-Graduação em Filosofia da UFOP, n. 27, dez. 2019, p. 2-26.

KRISTELLER, P. O. O sistema moderno das artes: um estudo em história da estética. II. Tradução: Anderson Bogéa. Artefilosofia, Revista do Programa de Pós-Graduação em Filosofia da UFOP, n. 30, jan-dez. 2021, p. 2-24.

LONGHI, R. Caravaggio. Tradução: Denise Bottmann. São Paulo: Cosac \& Naify, 2012.

NUNES, F.V.; SEREZA, L.C.; BOGÉA, A.; POSSARI, J. V.; BODNAR, T.; SANTIAGO, J., ANTUNES, D.; CASTRO, M. P. The Artworld - versão preliminar de teste. Curitiba, 2020. Disponível em: <https://sites.google.com/view/fabricaludi/jogos?authuser=4>. Acesso em 28 set. 2021.

NUNES, F. V.; BOGÉA, A.; SEREZA, L. C.; BODNAR, T.; POSSARI, J. V.; PAULA, B.; STRAPASSON, K. Gira-gira da arte - regras do jogo. Curitiba, 2021. Disponível em $<$ https://sites.google.com/view/fabricaludi/jogos?authuser=4>. Acesso em 28 set. 2021.

SCHILLER, F. A educação estética do homem: numa série de cartas. Tradução: Roberto Schwarz e Marcio Suzuki. 10a reimp. São Paulo: Iluminuras, 2017. (Biblioteca Pólen).

ROSENSTONE, R. A história nos filmes, os filmes na história. Tradução: Marcello Lino. São Paulo: Paz e Terra, 2010.

WITTGENSTEIN, L. Investigações filosóficas. Tradução: Marcos G. Montagnoli. $6^{\mathrm{a}}$ ed. Petrópolis, RJ: Vozes, 2009.

WHITE, H. Meta-História: a imaginação histórica do século XIX. Tradução: José Laurênio de Melo. 2a. ed. São Paulo: EDUSP, 2008.

WHITE, H. Trópicos do discurso: ensaios sobre a crítica da cultura. Tradução: Alípio Correia de Franca Neto. 2a. ed. São Paulo: EDUSP, 2014.

WHITE, H. (2018). O passado prático. Artcultura, Uberlândia, v. 20, n.37, p. 9 - 19, jul.-dez. 2018. 